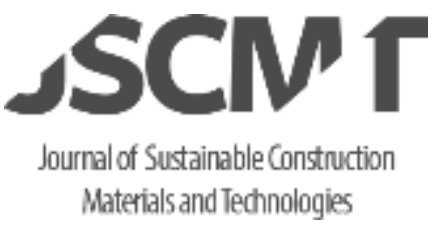

J Sustain. Construct. Mater. Technol. 3(3) (2018) 271-277 \begin{tabular}{c}
\hline \hline Journal of Sustainable \\
Construction Materials \\
and Technologies
\end{tabular}

www.eds.yildiz.edu.tr/jscmt

\title{
Seismic Isolation Systems Against Earthquake Disaster
}

\author{
Yunus UÇAR ${ }^{1, *}$ Mehmet Fatih ALTAN ${ }^{1}$ \\ ${ }^{1}$ Istanbul Aydın University Institute of Science and Technology, Halit Aydın Campus No:38 Küçükçekmece, \\ Istanbul/Turkey
}

Manuscript Received May 28, 2018; Accepted July 6, 2018

\begin{abstract}
Most of our country is located in the earthquake zone where active fault lines exist. Statistical analysis show that damaging earthquake occurs every 8 months in our country.The major devastations due to the 1999 Kocaeli and Düzce earthquakes have caused almost impossible losses to compensate for the country's economy. The health facilities damaged or destroyed in these earthquakes caused the disruption of the most needed health services after the earthquake, and hence increase of the losses. Seismic isolation can be defined as, considering the characteristics of earthquake acceleration, preventing damage to small or medium-sized earthquakes, and reducing the damage to large earthquakes by increasing the period and damping of the building. Seismic isolation is an earthquake-resistant structural design approach based on the principle of reducing the seismic force of the buildings by extending the period of the building, rather than increasing the seismic resistance capacity of the structure. The right applications of this technology allow buildings to be elastic even during major earthquakes.
\end{abstract}

Keywords: Earthquake, disaster, seismic isolation, base isolation, seismic isolator.

\section{Introduction}

$2 / 3$ of Turkey is under the risk of earthquakes with damaging intensity. Statistical analyses show that damaging earthquakes occur every 8 months in our country. Approximately 100,000 people died, and 495,000 buildings were destroyed at the time of 193 damaging earthquakes that occurred in the last century in Turkey. Only at the time of 1999 Kocaeli and Düzce earthquakes, about 20,000 people died, and 334,000 damaged buildings were detected, 124,000 of which were destroyed or severely damaged, 110,000 of which were moderately damaged, and 100,000 of which were slightly damaged. And economic loss caused directly by this earthquake reached 20 billion Turkish liras. [1]

Reducing these kinds of high risks is critical regarding the future and welfare of the country. In urban areas, geologic research is highly important for detailed detection of earthquake risks, and research under earthquake engineering is very important for determination of earthquake risks on existing structures, and for building new earthquake-resistant structures. Regional planning and sociological research should also be performed for risk reducing methods to be conducted in urban areas.

\section{What Is Seismic Isolation?}

\footnotetext{
* Corresponding author. Tel.: +90-555-967-5975

E-mail address: yucar@ipkb.gov.tr.
} 
It can be defined as allowing lower earthquake force to the structure by increasing its period and damping, preventing any damage to the structure under a minor or moderate earthquake intensity, and minimizing damage under high intensity, regarding the features of the structure and earthquake acceleration.

It is aimed to reduce the effects of an earthquake on the superstructure by ensuring displacements which are expected to arise during an earthquake to occur mostly on the seismic isolation floor, and the energy that occur due to earthquake to be absorbed by the seismic protectors on the same floor.

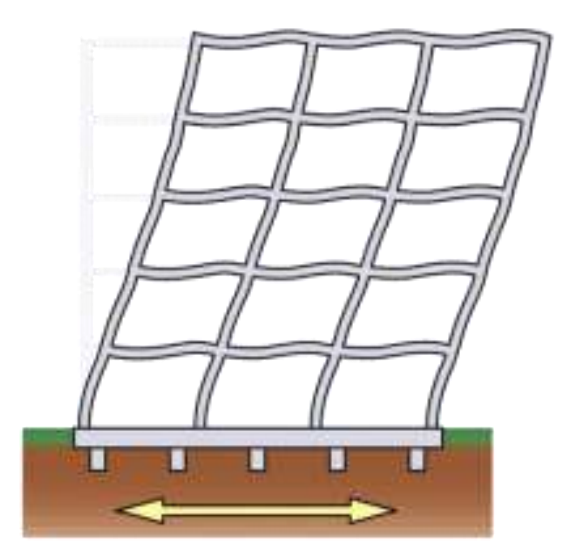

Building without a Seismic Base Isolation-

There are big translational motions between floors

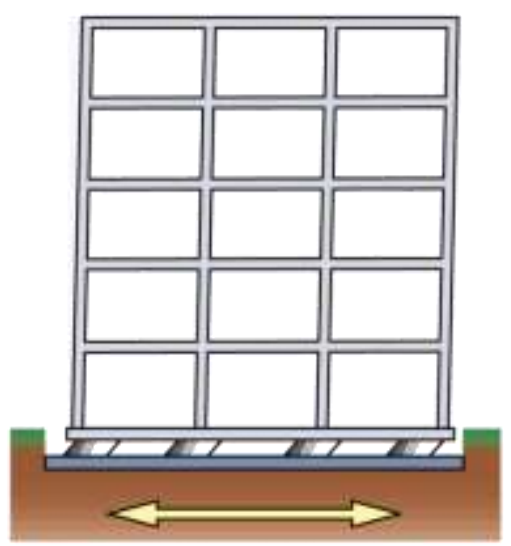

Building with a Seismic Base Isolation Displacement is mostly on the isolation floor [2]

\section{Seismic Isolation Systems}

One of the most important methods that can be used for planning of reducing the risks of earthquake is to equip buildings with seismic protection systems because it ensures life-span and maintainability of buildings, and the buildings can be used during and after an earthquake, by increasing the performance levels of the buildings against an earthquake.

\subsection{Historical Development of Seismic Isolation Systems}

Throughout history, people have had to face earthquake hazards and risks, and they developed various applications from time to time in order to eliminate these risks and minimize hazards they might encounter.

These include the grave of the emperor of Iran, Keyhusrev, (located near Shiraz) which was built only by piling stone blocks without using grout; molten lead poured between stone blocks used in the Ancient Greek and Roman columns, and thus trying to absorb the effects of an earthquake; and trying to reduce the risks of earthquake on Kutluğ Minaret (Harzem/Turkmenistan) through allowing the minaret to move during ground motion, as it is built on a reed field.

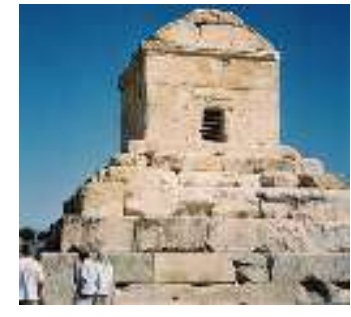

Fig.1. The grave of Keyhusrev
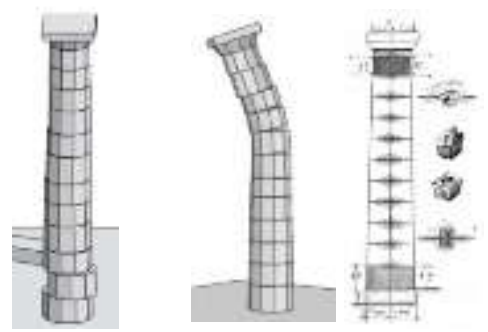

Fig.2. Ancient Greek and Roman Column

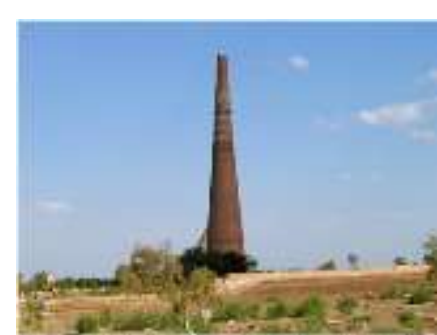

Fig.3. Minaret of Kutluğ Timur

Works on modern seismic protection systems emerged in 1900's. After 1970s, in parallel with the production and development of rubber, seismic protection systems started to be used on building systems. Thanks to these 
systems period of buildings becomes longer, and seismic force on buildings is reduced by increasing their displacement capacity. Based on this, in order to prolong period of buildings and reduce the effects of earthquake, friction pendulum systems also started to be used in 1980's.

\subsection{Tools Used in Seismic Isolation}

Seismic isolators consist of two types: one is elastomer-based (rubber), and the other is friction-based. Also, dampers are sometimes used to increase performance of buildings with or without isolators.

- $\quad$ Elastomer-Based Seismic Isolators

Natural Rubber Bearings (NRBs)

High Damping Rubber Bearings (HDRBs)

Lead Rubber Bearings (LRBs)

- $\quad$ Sliding-Based Seismic Isolators

Friction Pendulum Bearings (FP)

Straight Sliding Surface Bearings

- $\quad$ Dampers

Viscous Dampers

Steel Dampers

Tuned Mass Dampers

\subsubsection{Elastomer-Based Seismic Isolators:}

Natural Rubber Bearings (NRBs): Generally, they are used with dampers, sliding stiffness is almost linear. Damping value is $10 \%$. Deformation capability is high. Vertical load bearing capacity is low.
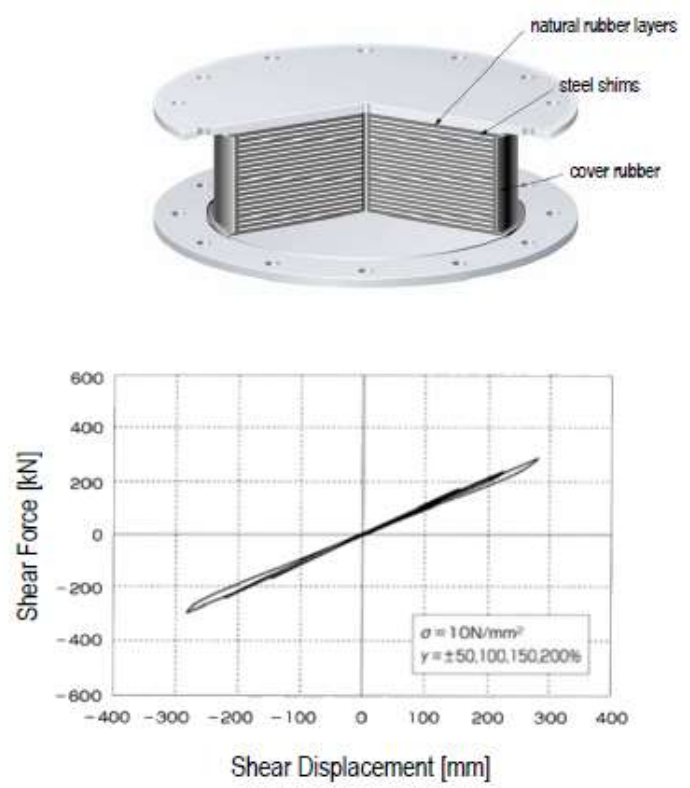

Fig.4. High Damping Rubber Bearings (HDRBs): Sliding stiffness is $3.5-12.6 \mathrm{kgf} / \mathrm{cm}^{2}$. Damping value is about $10-20 \%$. Deformation capability is high. It can bear up to $175 \mathrm{kgf} / \mathrm{cm}^{2}$ vertical loads. 

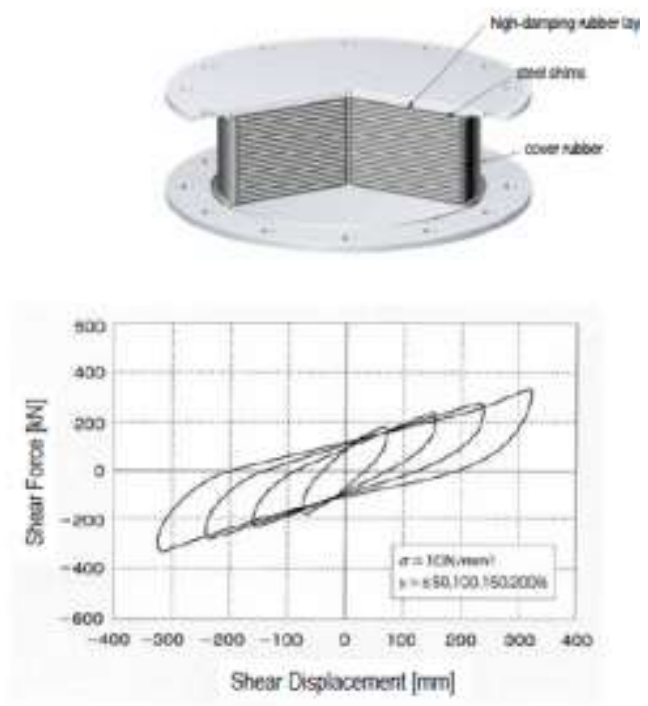

Fig.5. Lead Rubber Bearings (LRBs): Sliding stiffness is $4-12.6 \mathrm{kgf} / \mathrm{cm}^{2}$.Damping value is more than $30 \%$. Deformation capability is high. It can bear up to $175 \mathrm{kgf} / \mathrm{cm}^{2}$ vertical loads. It absorbs the earthquake energy with lead.
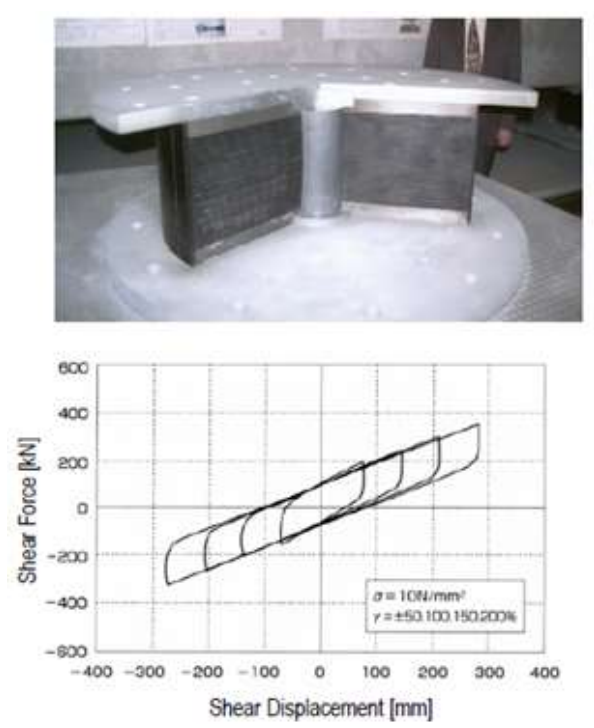

Fig.6. Lead Rubber Bearings (LRBS

\subsubsection{Sliding- Based Seismic Isolators:}

Friction Pendulum Bearing Isolators: There are single, double or triple friction pendulum types based on the concave surface the bearing moves on. Friction values are provided with teflon or other materials applied onto the stainless-steel concave surface. It is independent from the load on bearing period. The period depends on the geometry of concave surface on which the bearing moves.
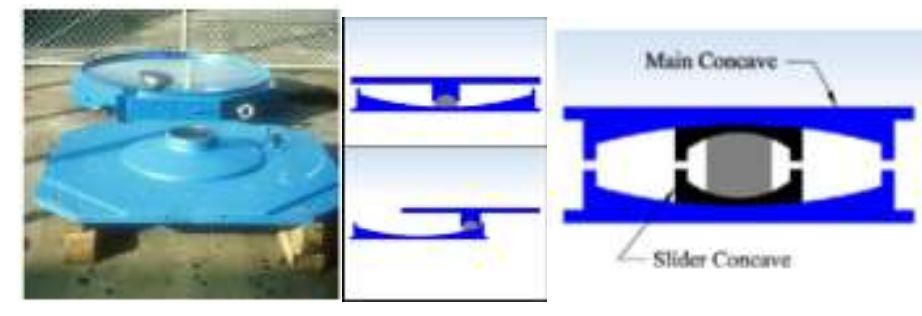
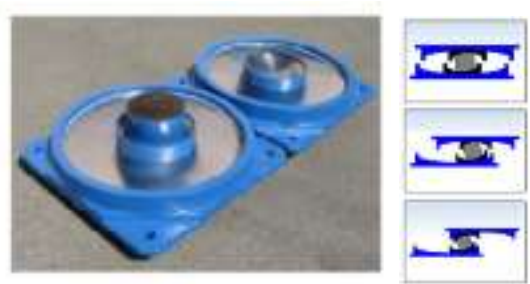

Fig.7. Single Friction Pendulum Bearing-

Fig.8. Triple Friction Pendulum Bearing [3] 
Straight Sliding Surface Isolators: There is no force that moves the bearing back to its position before earthquake. Thus, they are used with elastomeric bearings. Friction factor can be in the range of 0.02 and 0.15 .
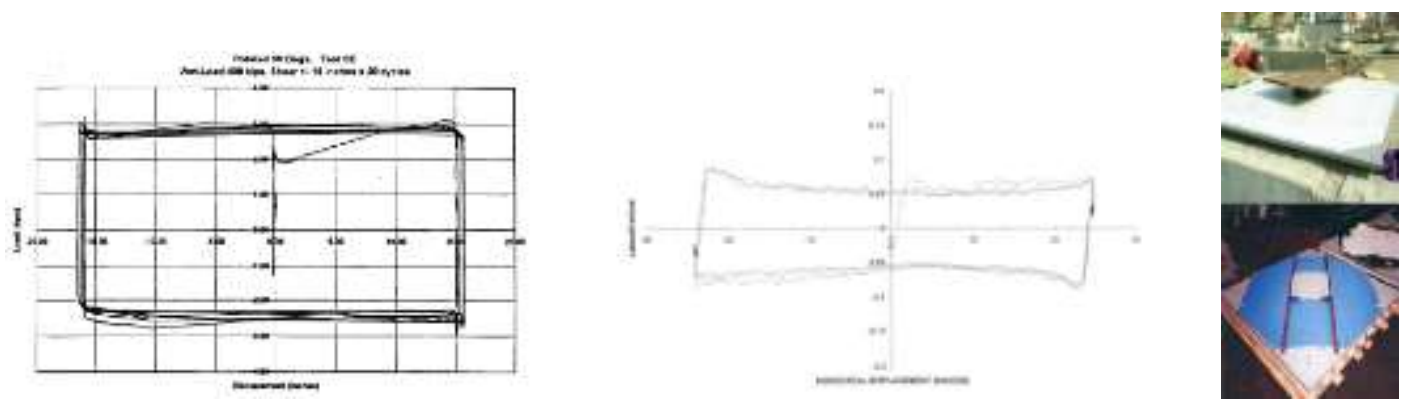

Fig.9. Straight Sliding Surface Isolators

\subsubsection{Dampers:}

Viscous Dampers: They function depending on building movement arising from the earthquake. Mechanical energy turns into thermal energy as a result of the movement of the piston through the fluid with high viscosity.
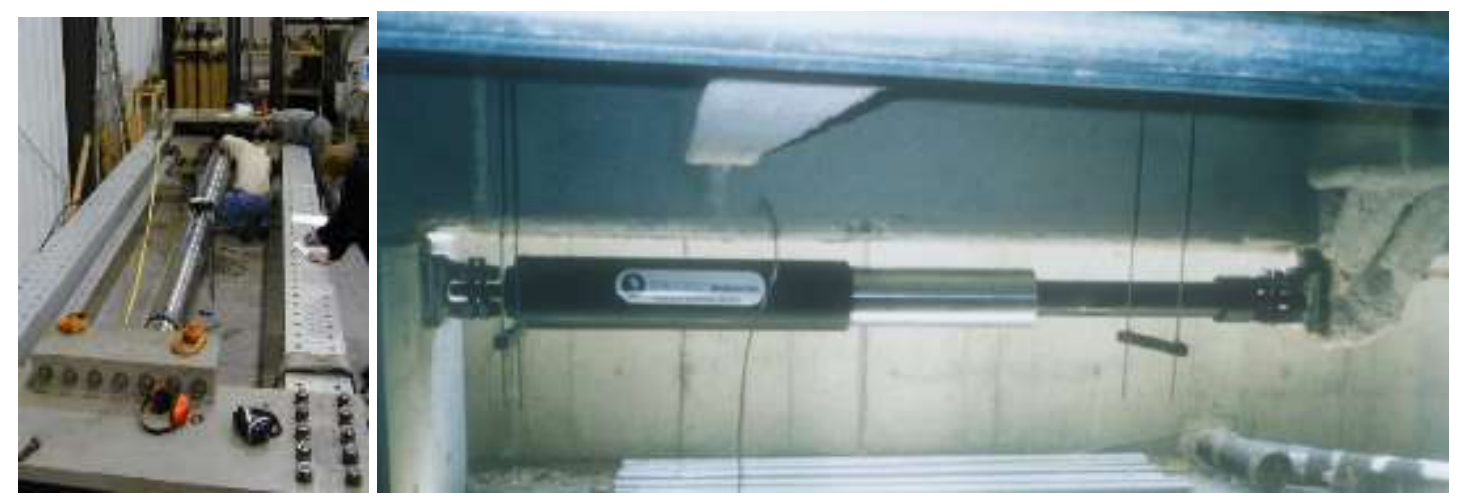

Fig.10. Steel Dampers: These dampers without a capacity of vertical load bearing are often used with elastomeric bearings. With these systems used commonly in Japan, earthquake energy is absorbed.
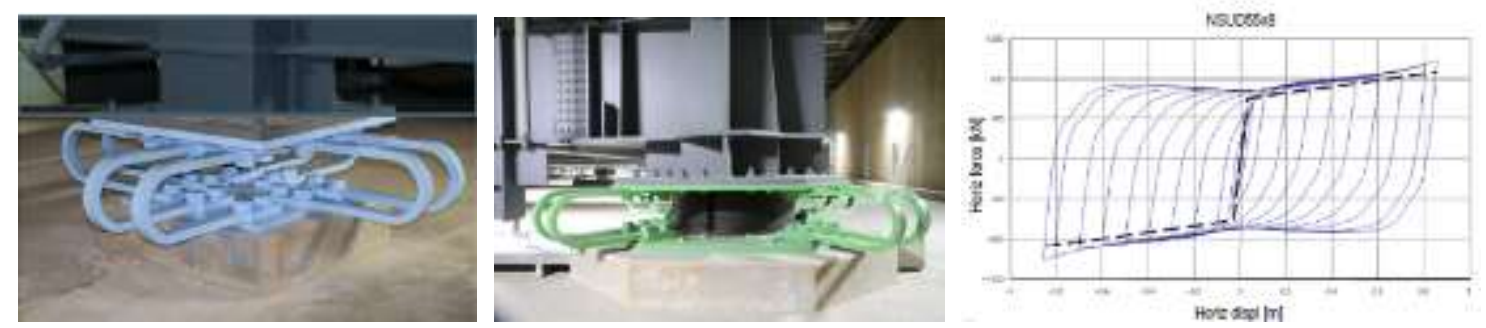

Fig.11. Tuned Mass Dampers (TMD): Mass connected to the main structure with the help of paralel spring and viscous dampers is called tuned mass dampers (TMD). If TMD parameters are selected properly and set by the vibration mood of the structure, a part of the vibration energy in this mood reduces the vibration energy of the main structure by providing flow to the TMD. [4]
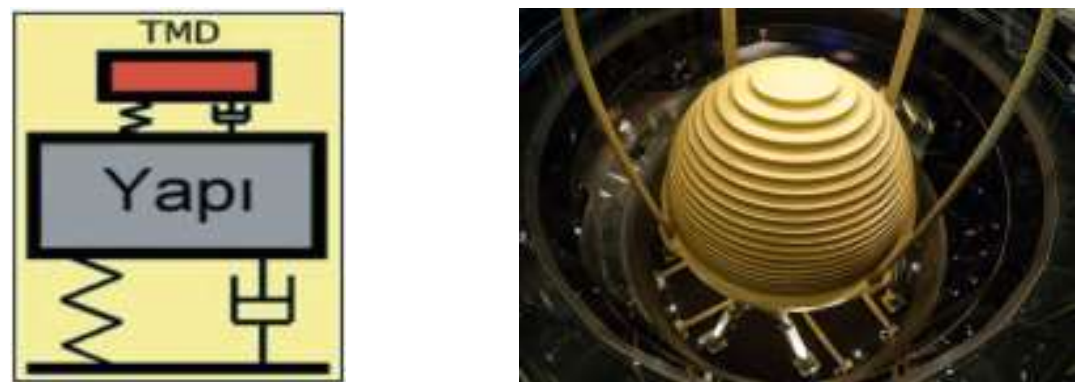

Fig.12. Tuned Mass Damper (TMD) 


\section{Control Systems}

Structure design can be divided into three stages. The stage where only static loads are taken into account for design is classical stage. Modern stage is where dynamic loads (affecting the structure) are also considered for design. The stage where temporal changes of the dynamic loads (affecting the structure) for the design are also considered is called post-modern stage.

\subsection{Active Control}

It is difficult to foresee the loads that will affect the structure. Thanks to the developments in computers, electro-hydraulic systems and sensor technologies, now dynamic forces can be measured, required control forces are calculated on the control computer according to a pre-defined algorithm, and these forces can be applied through active force mechanisms placed on the structure. In the post-modern stage, intended structure is an adaptable one, ensuring the safety, strength and comfort against dynamic environmental effects such as earthquake and wind.

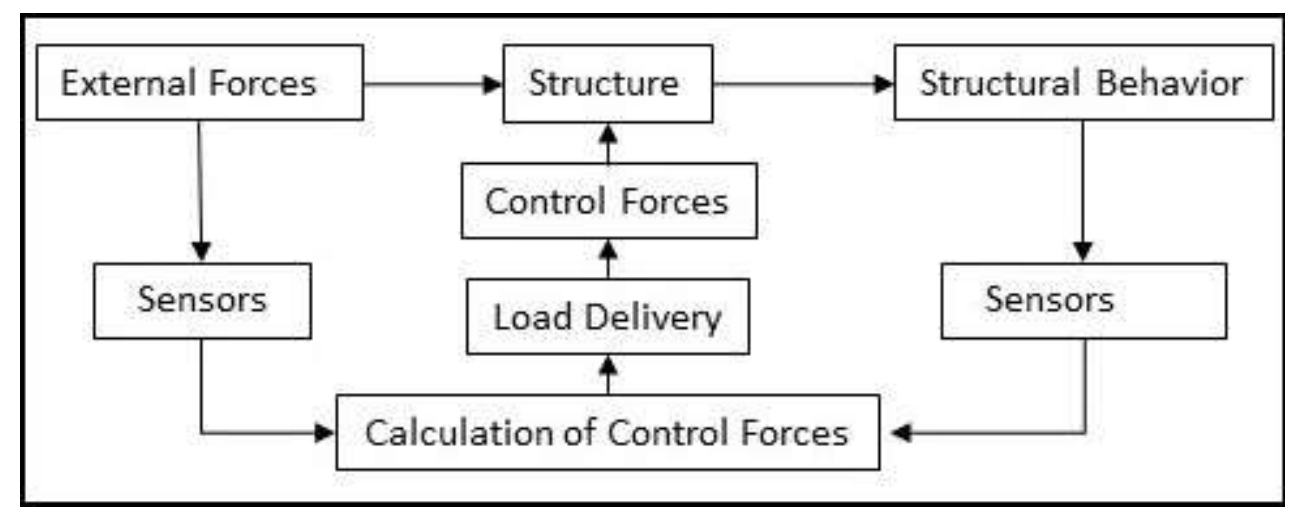

Fig.13. Diagram of Active Control

\subsection{Semi-Active Control}

Semi-active control systems, with need of lower external energy than active control systems, are one of the important developments. While the main power supplies of the active systems may be disabled during a seismic movement, batteries in the semi-active systems will keep working. The initial studies show that semi-active systems can have a better performance than passive systems or completely active systems. These systems are also used to damp high displacements of isolators in the buildings with isolators. Semi-active dampers function with the basis of controlling the mechanical features of fluids with the help of electrical or magnetic areas that can be generated with batteries).
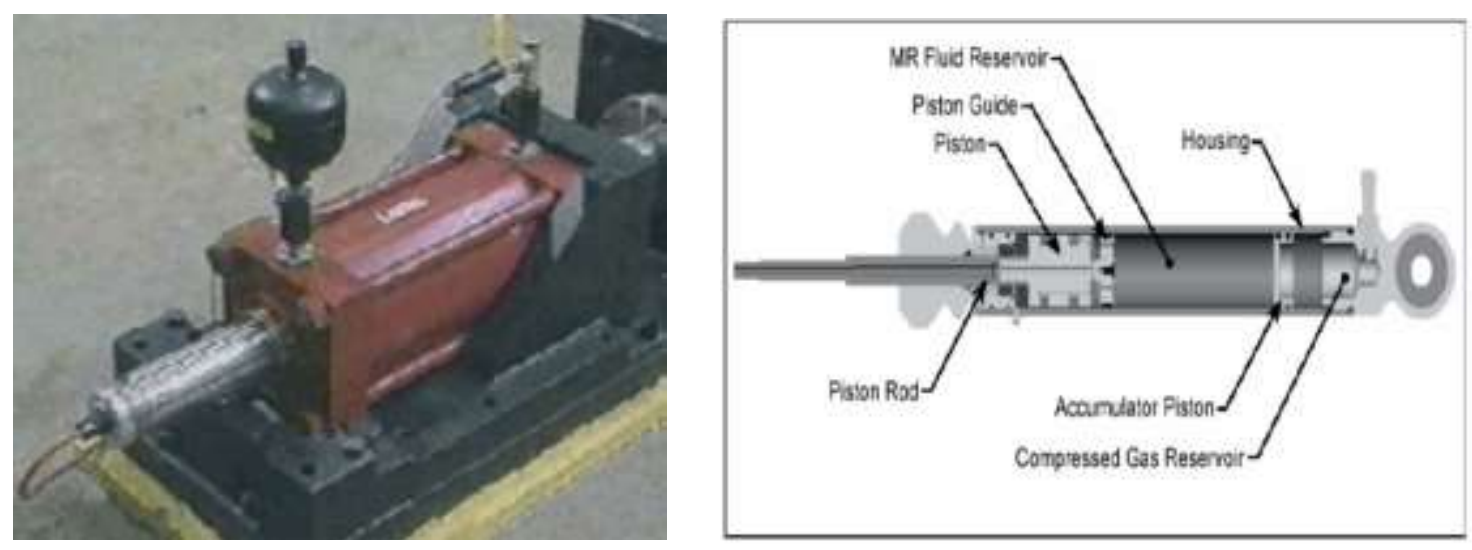

Fig.14.Combined Control

In combined structural control, structure is equipped with both active and half-active control systems, and also supported with passive elements to enhance its behavior. The aim is to reduce high energy need of active 
control elements, and at least to protect the structure with passive system if the energy for active system is interrupted during a seismic vibration.

\section{Conclusion}

In this study, worldwide developments on protecting the structures from dynamic effects such as earthquake are summarized. These technologies are commonly used especially in the USA and Japan, and it is inevitable for our country whose most parts are earthquake-prone to use these technologies. Design of three hospitals in Istanbul, each more than 250,000 sqm, were made by using seismic isolation systems, and construction process for these hospitals started in 2014. In addition, Marmara University, Marmara Başıüyük Training and Research Hospital is the biggest retrofit project with isolation system, and it is planned to open within 2018. As Ministry of Health requires all hospitals with 100 or more beds, which are on first- or second-degree seismic zone, to be built using these technologies, Turkey has become a marketplace for the manufacturers of these technologies. The buildings with seismic isolation, whose design were not made according to the current earthquake code and need follow-up for foreign codes, can be designed by Turkish engineers providing that new Turkish earthquake code which will be released in 2018 but effective in 2019 is followed.

\section{References}

1. Özmen, B. (2000). 17 Ağustos 1999 Depreminin Hasar Durumu (Deprem Raporu TDV/DR 010-53). Ankara; Türkiye Deprem Vakfi.

2. Url-2 < http://www.dis-inc.com >, erişim tarihi 21.02.2018.

3. Earthquake Protection Systems Inc. Technical Spesification of isolators

4. Dyke.S.J. , B.F. Spencer Jr., M.K. Sain, and J.D. Carlson, (1996) “Seismic response reduction using magnetorheological dampers" 